\title{
Molecular Mechanisms of Stress-Responsive Changes in Collagen and Elastin Networks in Skin
}

\author{
Jazli Aziz ${ }^{a} \quad$ Hafiz Shezalia ${ }^{a}$ amri Radzia Noor Azlin Yahya ${ }^{a}$ \\ Noor Hayaty Abu Kassim ${ }^{a}$ Jan Czernuszkab Mohammad Tariqur Rahman ${ }^{a}$ \\ ${ }^{a}$ Faculty of Dentistry, University of Malaya, Kuala Lumpur, Malaysia; ${ }^{b}$ Department of Materials, University of Oxford, \\ Oxford, UK
}

\section{Key Words}

Stress-strain - Connective tissue - Viscoelasticity · Fibroblast

\begin{abstract}
Collagen and elastin networks make up the majority of the extracellular matrix in many organs, such as the skin. The mechanisms which are involved in the maintenance of homeostatic equilibrium of these networks are numerous, involving the regulation of genetic expression, growth factor secretion, signalling pathways, secondary messaging systems, and ion channel activity. However, many factors are capable of disrupting these pathways, which leads to an imbalance of homeostatic equilibrium. Ultimately, this leads to changes in the physical nature of skin, both functionally and cosmetically. Although various factors have been identified, including carcinogenesis, ultraviolet exposure, and mechanical stretching of skin, it was discovered that many of them affect similar components of regulatory pathways, such as fibroblasts, lysyl oxidase, and fibronectin. Additionally, it was discovered that the various regulatory pathways intersect with each other at various stages instead of working independently of each other. This review paper proposes a model which elucidates how these molecular pathways intersect
\end{abstract}

\section{KARGER}

E-Mail karger@karger.com

www.karger.com/spp with one another, and how various internal and external factors can disrupt these pathways, ultimately leading to a disruption in collagen and elastin networks.

(c) 2016 S. Karger AG, Basel

\section{Introduction}

The skin is the largest organ in the human body and acts as the body's first line of defence, protecting the internal organs from external trauma and pathogenic infections [1]. It is composed of three layers (fig. 1): the outermost layer called the epidermis, the thicker and elastic middle layer called the dermis, and the inner layer called the hypodermis [2]. The dermal layer is what gives skin its strength and elasticity due to the high contents of collagen and elastin fibres [3]. High contents of collagen and elastin are mostly present in the reticular portion of the dermal layer.

Viscoelasticity, a reversible deformation property, allows the skin to stretch to a certain physiological limit under physical stress and then return to its resting state once the load is removed [1]. Sliding and realignment of collagen fibrils allows skin to deform while maintaining
(C) 2016 S. Karger AG, Basel

$1660-5527 / 16 / 0294-0190 \$ 39.50 / 0$
Mohammad Tariqur Rahman

University of Malaya

Wilayah Persekutuan

Kuala Lumpur 50603 (Malaysia)

E-Mail tarique@um.edu.my 
Fig. 1. Collagen distribution in skin anatomy. Compared to the upper dermal layers such as the epidermis and papillary dermis, the reticular region is rich in collagen and elastin fibres.

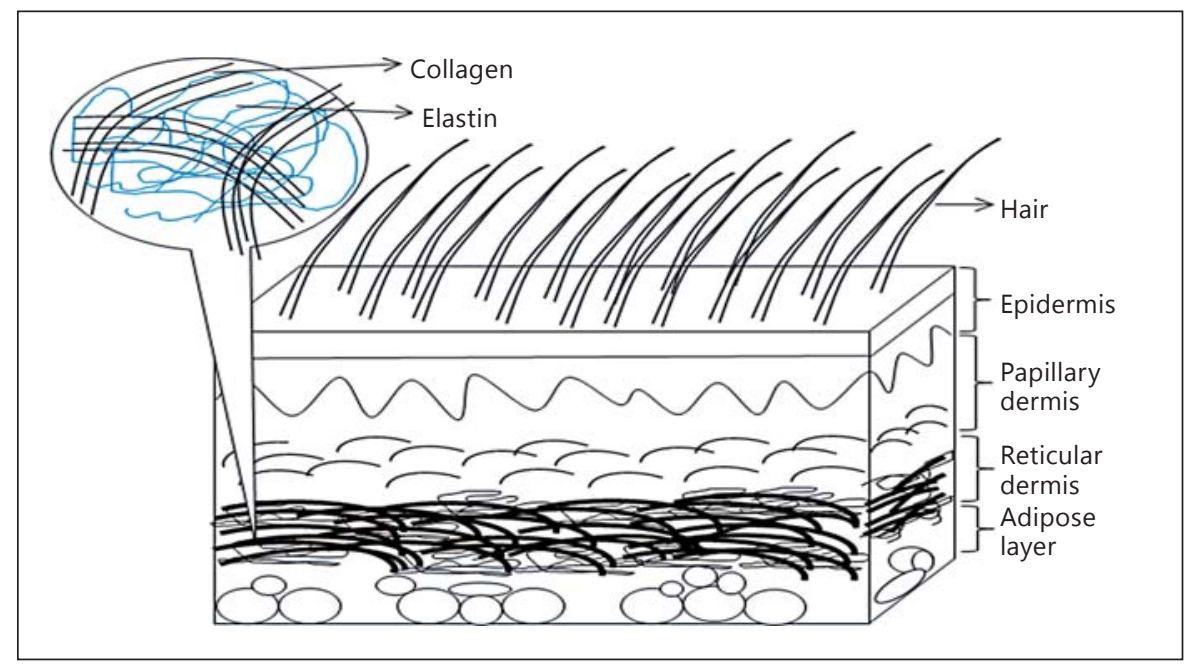

its integrity and preventing damage, while elastic fibres will return skin to its resting state after the external force is removed [4]. Other than mechanical stress, biological (cancer and aging) and environmental factors (sunlight and ultraviolet, UV) are also capable of altering the architecture and structural properties of the collagen and elastin networks in skin [5].

The physiological changes that occur in skin following exposure to these factors may interrelate and influence one another. A combination of exposures might also have a compounding effect due to the interrelated nature of their physiological responses. This review aims to highlight the structural and mechanical properties of collagen and elastin in skin and to describe of how various factors can affect or alter these properties.

\section{Collagen Synthesis and Classification}

Collagen is the most abundant structural protein in the body and can be found in connective tissue, bone, cartilage, and skin $[5,6]$. Collagen can be organized into various structural conformations, such as fibrillar collagen, basement membrane collagen, fibril-associated collagens with interrupted triple helices, and transmembrane collagen [7]. Fibrillar collagen which can be found in abundance in human skin will be the focus of this review. In skin, collagen fibres constitute three-quarters of its dry weight $[8,9]$. There are several hierarchical levels involved in the formation of collagen (fig. 2). The lowest order structure is known as tropocollagen, which is a righthanded triple helical structure comprised of 3 polypeptide

Stress-Responsive Changes in Collagen and Elastin Networks in Skin chains [10]. Hydrogen bonds that form within the triple helical structure provide stability and are the most abundant in the animal kingdom [9]. Covalently cross-linked tropocollagen molecules form polymeric collagen fibrils, and collagen fibrils aggregate to form collagen fibres [11]. The combination of polypeptide chains that form tropocollagen determines the types of collagen fibrils to be formed. To date, 46 different polypeptide chains have been identified, which are synthesized by genes named after the type of polypeptide chains they produce. For example, COL1A1 is the gene which synthesizes the alpha- 1 chain of collagen type I, while COL4A6 synthesizes the alpha- 6 chain of collagen type IV. These 46 polypeptide chains can combine to form 28 different types of collagen $[12,13]$. Collagen type I and type III are predominant in skin, and can be found in abundance in the dermal layer, while collagen type V, VI, VII, and XI can also found throughout skin in varying amounts $[9,14]$.

\section{Collagen Fibril Structure and Biomechanical Properties}

Collagen fibrils have been extensively studied to determine their structural and biomechanical properties $[6,15$, 16]. Tropocollagen molecules, the basic structural units of collagen, measure approximately $1.6 \mathrm{~nm}$ in diameter and $300 \mathrm{~nm}$ in length [17] and stack in a formation known as the quarter-staggered assembly [18]. The spirally coiled tripeptide structures of tropocollagen are stabilized by interchain $\mathrm{H}$-bonds while wrapping around each other (fig. 2). This arrangement of molecules leads to the de- 


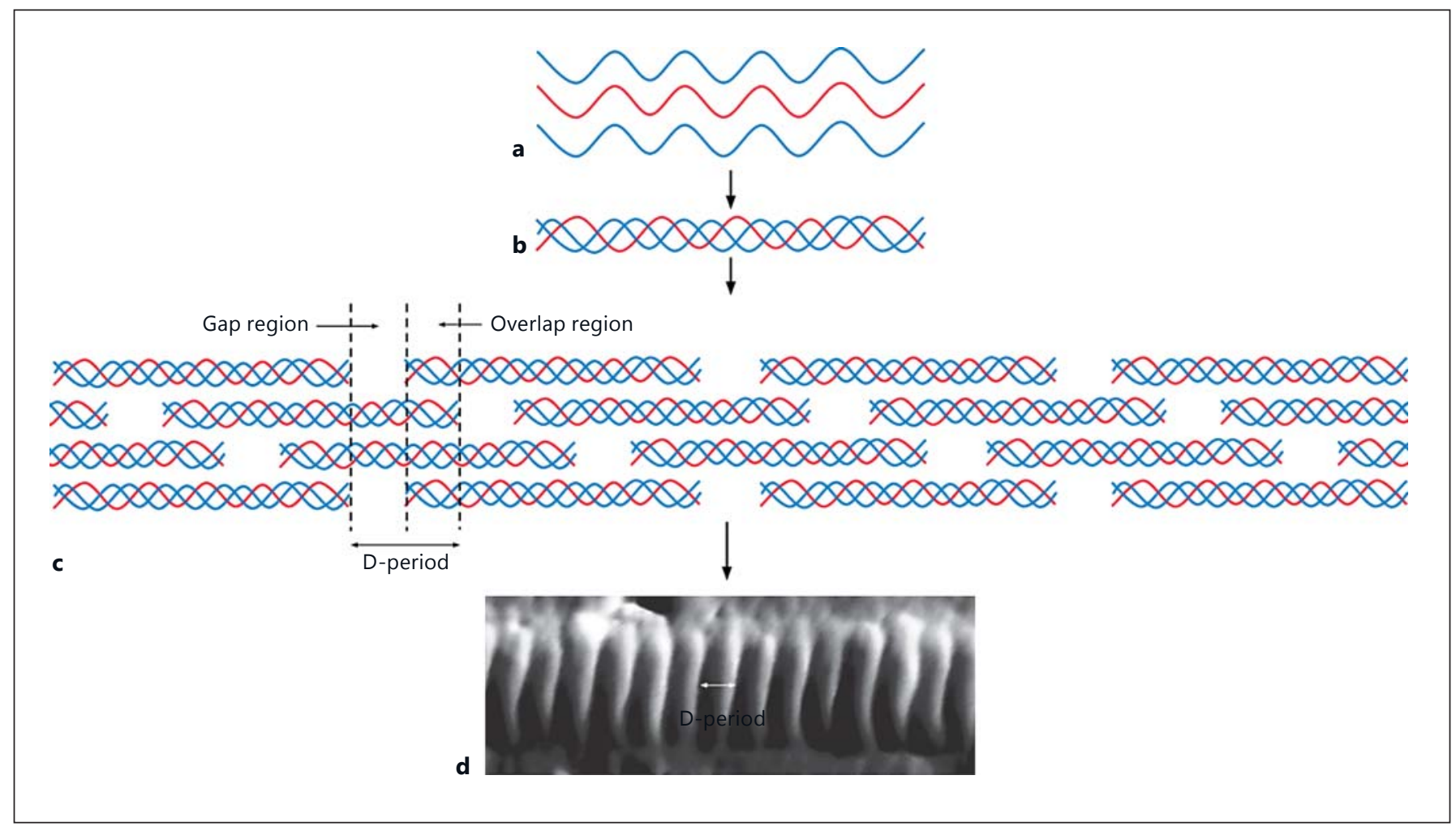

Fig. 2. Collagen synthesis: 3 polypeptide chains (a) form a triple helical structure known as tropocollagen (b). Tropocollagen molecules will then stack in a quarter-staggered formation (c), giving rise to overlap and gap regions which give collagen fibrils their distinctive banding pattern, known as a D-period (d). The atomic

finitive banding patterns seen in collagen fibrils, where overlap and gap regions alternate along the fibril. Adjacent overlap and gap regions form a $\mathrm{D}$-period measuring approximately $67 \mathrm{~nm}$, where overlap regions measure approximately $31 \mathrm{~nm}(0.46 \mathrm{D})$ and gap regions measure $36 \mathrm{~nm}(0.54 \mathrm{D})$.

It has been established that the properties of collagen molecules (fibrils) are reflected in the higher order structures they form (fig. 3) due to their high abundance, such as tendon, ligaments, and skin [19-21]. Young's modulus $(\mathrm{YM})$ is a common property of collagen and collagenous tissues that is measured as a means to describe its biomechanical properties. It is defined as the ratio of stress to strain [6]. In other words, YM describes the intrinsic ability of materials to resist deformation when physical force is applied [22]. Collagen and collagenous tissues display a unique property where stiffness dramatically increases as strain is applied [23]. The stress exhibited by collagenous tissues is approximately exponential to the strain applied [24]. Different collagenous tissues have different force microscope image (d) was taken using a NanoWizard ${ }^{\circledR} 3$ atomic force microscope (JPK Instruments, Germany) at the Faculty of Dentistry, University of Malaya. The image shows a collagen fibril present in scalp skin of a Dorper sheep.

YM values; however, these values vary greatly due to a number of factors. Function is the strongest determinant of a tissue's YM. Tissues such as skin, lungs, and blood vessels must be able to withstand elastic extension but do not require a lot of force to deform, which equates to a relatively lower YM value. Other structural tissues such as cartilage and bone must be strong enough to withstand compression forces and thus tend to have higher YM values by comparison [25].

A large degree of variation exists in reported YM values even for the same tissue type. Such variation is attributed but not limited to in vivo versus ex vivo measurements, hydration level of tissue samples, time lapse during post-mortem tissue sample collection, temperature of sample storage and at the time of YM measurement, and methods of measuring YM such as indentation or tensile methods [22]. Skin has been reported to exhibit YM values ranging from $6 \mathrm{kPa}$ to $50 \mathrm{MPa}$ when measured by indentation, but from 21 to $39 \mathrm{MPa}$ while measured by tensile stretching [22]. 


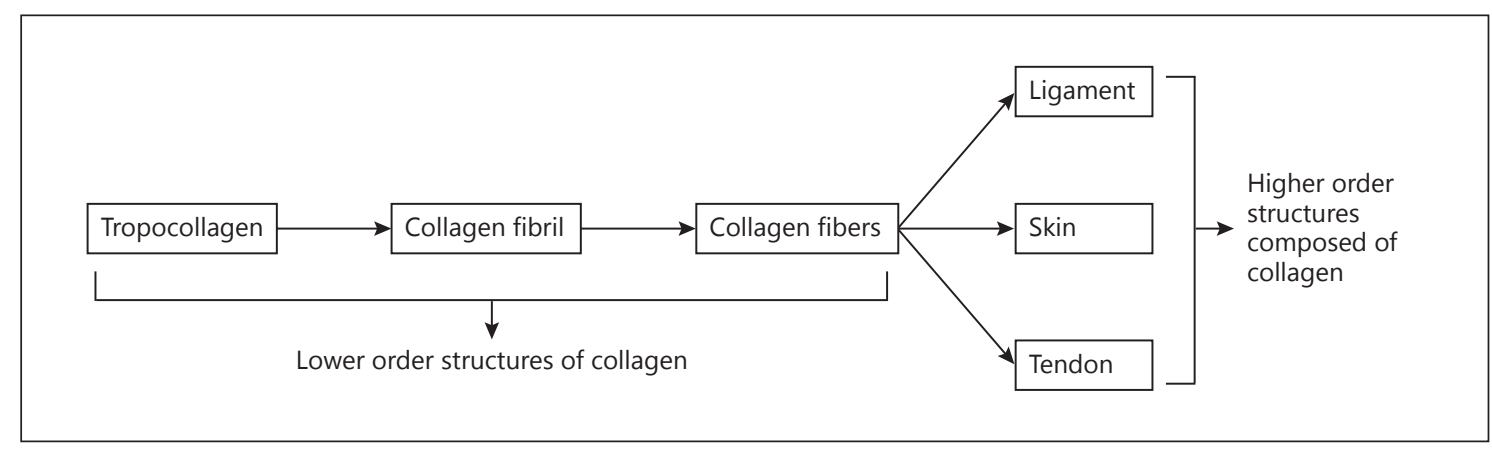

Fig. 3. The biomechanical properties of collagen at the molecular (lower order) level are reflected in the tissues (higher order) they form.

Like most biological samples, the stress-strain curve of collagenous tissues such as the skin (fig. 4) is non-linear [26]. The curves of collagenous tissues are also J-shaped and are usually divided into three regions [19, 27-29]. The first is known as the toe region, and corresponds to the part of the curve that is most parallel to the $\mathrm{x}$-axis, usually up to strains of about 0.3 . During this stage, microscopic crimps in collagen fibrils are removed, and collagen offers little resistance to the applied stress. This is due to the naturally wavy and bundled nature of collagen. The behaviour of skin at this stage is dominated by elastic fibres [1], and low amounts of stress are sufficient to cause large deformations. This contributes to the low strain at this region of the curve. At higher strains the slope of the curve increases, and this region is known as the heel region. Molecular kinks in the gap regions of fibrils begin to straighten out, and fibrils begin to stretch and realign in the direction of the applied stress. This stage of the stress-strain curve is when collagen begins to resist deformation, and higher amounts of stress are required to continue deformation of tissue. The final stage of the stressstrain curve is called the linear region and corresponds to the region of the curve with the highest slope. Collagen fibrils have already realigned, and kinks in the gap region have straightened in the direction of the applied force. Hence, under high stress, deformation is probably caused by the gliding of neighbouring collagen molecules or the stretching of tropocollagen molecules within the fibrils themselves. Under certain in vitro conditions, however, a fourth region can be observed. During this stage, the amount of strain applied to collagenous tissues is too great, which brings fibrils past their yield point and ultimately leads to failure, where some fibrils will break [21, $28]$.

\section{Elastin Framework, Synthesis, and Assembly}

The extracellular matrix (ECM) of vascular and other connective tissues consists of a network of elastic fibres. The biosynthesis of elastic fibres is a complex process, beginning with the synthesis of the soluble form of elastin, known as tropoelastin, which is post-translationally modified, packaged, assembled, cross-linked, and transported to the ECM to form bundles of mature elastic fibres. Elastic fibres, the most crucial part in the ECM, are comprised of two main components: (i) a core of polymeric insoluble elastin and (ii) a peripheral mantle of tubular-appearing microfibrils [30]. Microfibrillar scaffolds will determine the shape and orientation of elastic fibres once tropoelastin molecules are deposited [31,32]. Elastin contains a number of hydrophobic amino acids, such as valine, alanine, glycine, and proline [33]. Elastin is most abundant in elastic fibres, which contributes to the characteristic properties of elastic recoil.

While collagen contributes tensile strength to skin, elastic fibres contribute extensibility and reversible recoil to skin, which allows it to withstand repeated mechanical deformation without suffering irreversible plastic damage [34]. Stress-strain curves of skin (fig. 4) largely illustrate properties of collagen due to its high abundance; however, in the toe region of the curve, mechanical properties of skin reflect those of elastic fibres [1].

Verhoeff staining with van Gieson counterstain enables the differentiation of blue-black elastin from collagen and smooth muscle [35]. Other types of stains for elastin include Luna's aldehyde fuchsin stain [36] and Weigert's resorcin-fuchsin staining [37]. Under light microscope, the elastic fibres typically appear in a wavy pattern [33]. The elastic fibres, unlike collagen, can be stretched and retracted. The presence of these fibres al- 
Fig. 4. The stress-strain curve for skin, with collagen morphology at each respective stage. a Toe region. b Heel region. c Linear region. d Fourth region: under certain in vitro conditions, a fourth region can be observed. During this stage, the amount of strain applied to collagenous tissues is too great, which brings fibrils past their yield point and ultimately leads to failure, where some fibrils will break.

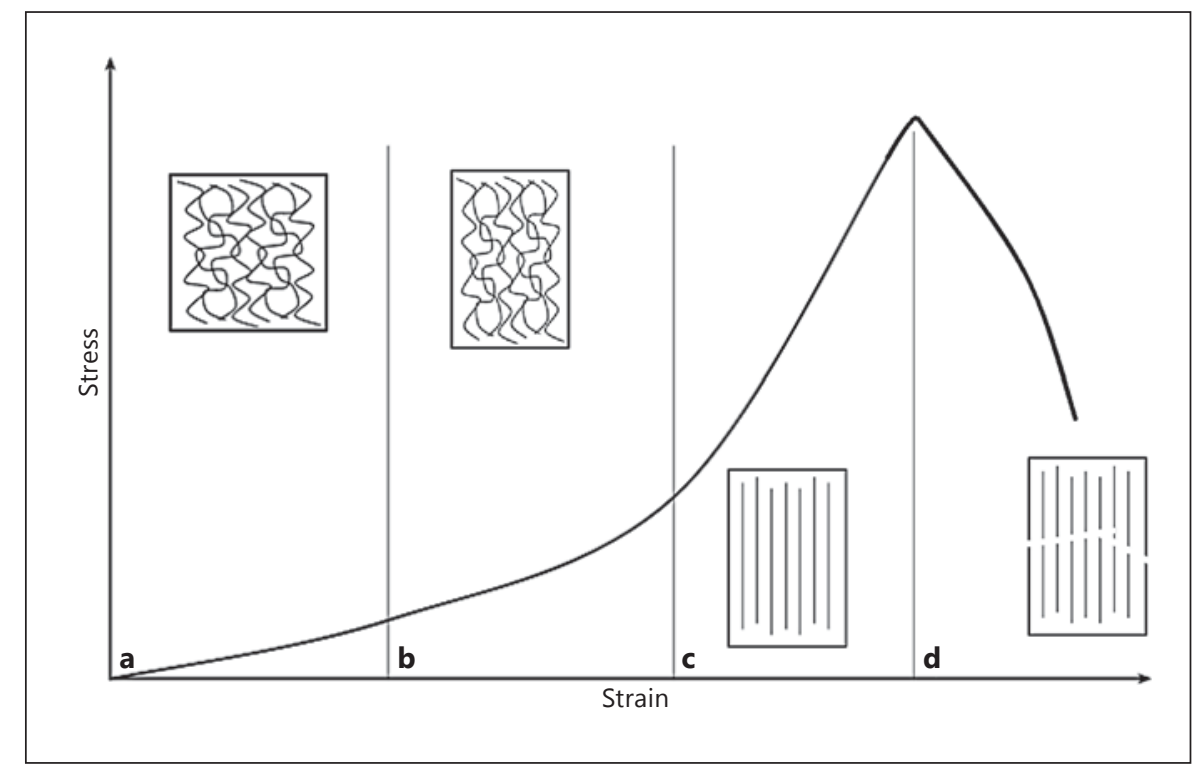

lows the skin to revert back to its original conformation after the removal of any deforming forces [38]. It has been observed that in reticular dermis, the elastic fibres appear coarse and entwined with collagenous fibre bundles, while the papillary dermis exhibits finer elastic fibres that rise up towards the epidermis [39]. In normal tissue the elastin shows a typical candelabra-like pattern oriented perpendicular towards the basal lamina [40].

The fibroblasts are a major group of cells in the dermis involved in elastogenesis [41]. The process of elastogenesis occurs mainly in the dermis, especially in the superficial dermis. During the elastogenesis process, the tropoelastin monomer is synthesized on the rough endoplasmic reticulum and undergoes little intracellular post-translational modification [42]. During this phase, the elastin-binding protein associates with tropoelastin monomers to become a complex form before being released on the cell surface [43]. This association of elastinbinding protein and tropoelastin monomers protects the insoluble elastin from proteolysis and gives it extraordinary stability [44]. It has previously been reported that aldosterone upregulates the synthesis of tropoelastin and procollagen [45]. The tropoelastin monomers undergo self-assembly by having an elastic N-terminal coil region and a cell-interactive $\mathrm{C}$-terminal foot region cross-linked together to form a highly exposed bridge region on microfibrils $[30,46]$. Thus during self-assembly of the tropoelastin, fibulin-5 and fibulin- 4 have the potential to induce elastic fibre formation and also promote the coacervation process $[47,48]$.
Tropoelastin is soluble in cold aqueous solutions of less than $20^{\circ} \mathrm{C}$. Alternatively, the tropoelastin monomers can assemble in the absence of microfibrils on the cell surface [49]. The microfibrils are the first visible component to appear in low abundance in elastic fibres. Lysyl oxidase (LOX) can increase the cross-linking efficiency of tropoelastin monomers by oxidative deamination of lysine residues which forms allysine, resulting in mature insoluble elastic fibres [50]. The formation of desmosine and isodesmosine cross-links via allysine-allysine or allysine-lysine reactions also contribute to the biomechanical properties of elastic fibres, as these cross-links can resist elastolysis [51]. Collectively, these cross-links give elastic fibres an incredible durability, with a half-life of approximately 74 years [52]. When LOX is inhibited cross-linking is greatly reduced, which can lead to the formation of disorganized connective tissue [50]. The degradation of elastic fibres can happen when the concentration of matrix metalloproteinases (MMPs) is elevated in the pathway [53].

\section{Factors that Affect Collagen and Elastin Dynamics}

\section{Biological Factors}

\section{Genetic Mutations}

More than 1,000 mutations have been identified in more than 20 genes for 12 different types of collagen [54, 55]. Of those, approximately 250 mutations affect collagen type I, affecting the genes that encode for both 
COL1A1 and COL1A2 polypeptide chains [56]. Many of these mutations have been identified in patients suffering from osteogenesis imperfecta, a disease which affects many collagenous tissues. The substitution of glycine residues which are involved in hydrogen bonds often causes the most damage, and the location of the substitution as well as the identity of the replacement amino acid can impact pathology $[57,58]$. Mutations often cause the formation of null alleles, as premature termination codons are created in the genes. Symptoms are spread across different parts of the body that are rich in collagen type I, such as brittle bones, blue sclerae, abnormal teeth, weak tendons, and thin skin $[59,60]$.

Ehlers-Danlos syndrome (EDS) is a collection of heterogeneous genetic disorders that cause joint hypermobility, skeletal disorders, and rupturing of hollow organs, and can also affect the skin's extensibility, thinness, and fragility. There have been at least 9 subtypes of the disease that have been identified, with types I and II primarily affecting collagen type $\mathrm{V}$ synthesis, but also type I collagen. These subtypes can be characterized by atrophic scars and hyperextensibility of the skin. Ehlers-Danlos syndrome type IV, on the other hand, is the most severe subtype, affecting collagen type III. The COL3A1 gene is the primary target of this subtype, with over 100 mutations identified in this gene. The severity of this subtype is due to the possibility of rupturing of large arteries of other hollow organs [61].

Some other forms of genetic diseases that affect collagen include Alport syndrome, a consequence of COL4A3 and COL4A5 mutations [62, 63], Bethlem myopathy, which follows mutation to the COL6A1 gene [64], and multiple epiphyseal dysplasia and autosomal recessive Stickler syndrome, which occur following mutations to the COL9A1, COL9A2, COL9A3, COL11A1, and COL11A2 genes [65].

Cutis laxa (CL) is a rare disorder which affects elastic fibre assembly. Abnormalities in elastic fibres affect several body systems such as the respiratory system, circulatory system, and digestive system by reducing the elasticity of organs such as the lungs, aorta, and gastrointestinal tract, respectively [66]. The most obvious clinical manifestation, however, affects the skin. Patients with CL often have loose saggy skin, drooping cheeks, and a prematurely aged appearance. The cause of such symptoms is a reduction in the size and volume of elastic fibres, in addition to a disruption to normal elastic fibre arrangement $[67,68]$. CL can be inherited via both the autosomal recessive and autosomal dominant pathways. Autosomal recessive inheritance is caused by mutation to the gene

Stress-Responsive Changes in Collagen

and Elastin Networks in Skin encoding for fibulin-5. This form of CL is the most severe, as most children suffering from this disorder die during infancy due to cardiopulmonary complications [69-72].

Cancer

Cancer has traditionally been identified as a disease of rogue cells. However, the current consensus is that cancer is actually a disease of imbalance, where the body is unable to effectively deal with rogue cells [73]. One of the major contributing factors to this condition is a disruption to the homeostasis of the ECM. As a major regulator of cellular and tissue function, disruption to the homeostatic environment of the ECM acts as a key component of tumour stroma [73]. Since collagen accounts for the majority of the ECM, its increased or decreased rate of synthesis as well as structural changes can affect tumour malignancy $[74,75]$. MMPs and tissue inhibitors of metalloproteinases are vital in the regulation of ECM homeostasis and work in cohesion to strictly regulate collagen degradation [76]. An imbalance in the concentration of MMPs and tissue inhibitors of metalloproteinases can lead to aberrant MMP proteolysis, which has been frequently recorded in cancer cases [77].

During tumour progression, the ECM undergoes considerable structural changes, including increased synthesis and deposition of proteoglycans, fibronectins, and collagen, specifically types I, III, and IV [78]. In healthy tissues, the collagen surrounding epithelial structures is commonly smooth and curly. However, as tumours begin to develop, the collagen gradually thickens, straightens out, and becomes stiff. Stiff collagen matrices have been shown to increase prolactin secretion in vitro. This promotes tumour metastasis and progression by enabling cell migration into the ECM [79]. Intravital microscopy of breast cancer tissue has also shown cancerous cells migrating rapidly along collagen fibres [80].

The stiffening of collagen, and ECM as a whole, is achieved via several mechanisms. LOX-dependant crosslinking of collagen and elastin fibres is one such mechanism. LOX is synthesized by fibroblasts during the early onset of carcinogenesis and later by hypoxic tumour cells. LOX induces cross-linking between collagen and elastin, which increases insoluble matrix deposition that leads to tissue stiffness [81]. Fibronectin-mediated collagen reorganization is another mechanism which leads to ECM stiffening. Dynamic interactions between fibronectin and collagen are likely to induce tumour progression. In fact, fibronectin has previously been implicated in the early stages of cancer metastasis [82, 83]. Osteonectin, a multifunctional glycoprotein also known as SPARC (secreted 
protein acidic and rich in cysteine), is involved in the stiffening of ECM. It is synthesized by both fibroblasts and tumour cells and has a high affinity for collagen types I and IV. Calcium binds to osteonectin, which in turns causes the stiffening of collagen and ECM [74].

\section{Aging}

Mechanisms that cause skin aging can be both intrinsic and extrinsic in nature [84]. Intrinsic aging involves changes to natural biological processes such as deceleration of regenerative capacity, while extrinsic aging involves exposure to environmental influences like UV radiation and environmental pollutants [84]. The relative volume (percent) and quality of elastic fibres and collagen in the skin significantly varies with age [5]. Elastic fibre disintegration has been reported in individuals aged between 30 and 70 years in small amounts; however, a larger amount of disintegration was observed in individuals older than 70 years [41]. The synthesis of elastic fibres is continuous during our lifetime but reportedly ceases after the age of 50 [41]. Thus, the arrangement of elastic fibres appears loosely packed and fine with short fragmented microfibrils in older individuals compared to younger individuals $[41,85]$. When younger skin suffers actinic damage, fine structural changes are noticed which are similar to those in elderly undamaged skin [86]. Tropoelastin mRNA decreases about $45-50 \%$ with increase of age because elastogenesis declines slowly [87]. Moreover, the activity of soluble LOX increases with aging, whereas that of insoluble LOX reduces at 60 days old [88].

When comparing between young and old age, young age will have numerous fibroblasts in both the papillary and reticular dermis with a high number of type I collagen and elastin mRNA, whereas old age will reduce the cell numbers and silver grains per cell as measured by in situ hybridization [89]. The newborn rat has a highly intense deposition of silver grains but significantly reduced solubility [88]. The loss of ECM such as decreased biosynthetic capacity of the remaining cells, cell loss, and a progressive increase of matrix-degrading enzymes are evident when histological skin sections from young and old individuals are compared [90]. The elastase-type protease in vivo and in vitro was upregulated, underlying the aging process [91]. During the aging process, the elastin fibres are degraded, there is an increase of fine collagen in the papillary dermis with a strong increase of fibronectin, and the collagen/elastin ratio increases. Intrinsically, aged skin shows general atrophy of the ECM with a decrease of elastin and thickness in the interstitial collagen of the fibrils [92].

\section{Physical Factors}

Mechanical Stretching

Skin is able to withstand certain amounts of physical force (measured as stress per unit area) by deforming (measured as strain or proportional deformation). Once the force is removed, skin returns to its resting state, which is possible due to the viscoelastic property of the skin. This biomechanical property of the skin is contributed by collagen and elastin fibrils [4]. The viscous component of skin involves the gliding of collagen fibrils during realignment in the direction of the applied force. This dissipates the energy applied by the external force and allows the skin to deform to a certain limit without suffering severe damage $[4,93,94]$. Elastin fibres contribute to the elasticity of the skin by storing energy from the applied force, and ensures the skin is able to return to its original resting state after the removal of the force $[27,93]$.

Mechanotransduction describes the physiological response of cells to physical applications of stress. Cells will recognize mechanical loads as stimuli and transmit appropriate signals to the constituents of the ECM such as collagen and elastic fibres, transmembrane receptors such as integrins, actin filaments, and non-muscle myosin [95]. The cyclic stretching of cells such as fibroblasts activates genetic expressions for the constituents of the ECM such as collagen and fibronectin, which often leads to the assembly of dense ECM that is rich in collagen [96]. Newly synthesized collagen and fibronectin fibrils will align in the same direction as the applied force [97].

\section{Striae Gravidarum}

Striae gravidarum is a phenomenon where stretch marks appear on the skin of women during pregnancy. These marks appear as erythematous bands on several parts of the body, including the abdomen, breasts, hips, and thighs. They usually start appearing from the 24th week of gestation [98]. The exact mechanism that leads to striae gravidarum is yet to be elucidated, but it is clearly related to the alteration in dynamics of skin connective tissue $[99,100]$. A combination of mechanical stretching and hormonal factors are reported to be vital in the aetiology [101]. Hormones such as relaxin, oestrogen, and adrenocortical hormones are believed to reduce the adhesiveness of collagen fibres. They also alter the structure of both collagen and elastin fibres, making them less prone to stretching. The increased effect of hormones is believed to be due to the upregulation of receptor expression, as receptors for oestrogen, androgen, and glucocorticoids are found to be more abundant in striae compared to nor- 
mal skin [102]. Stretching of the skin also makes the epidermis thinner, making stretch marks more visible [103, 104].

\section{Controlled Tissue Expansion}

Tissue expansion is a surgical technique that dates back to the late 1950s [105] where expanders are implanted beneath the skin and allowed to swell, thus stretching skin to the point where newly synthesized skin is formed $[2,106]$. When skin is physically stretched beyond its physiological limit, the resting tension and homeostatic equilibrium are interrupted. This initiates a cascade of molecular pathways which work in unison to restore the homeostatic equilibrium state by increasing the surface area of the skin $[107,108]$. The interrelated pathways which are triggered following homeostatic disruption involve the ECM, cell membranes, enzymatic activity, secondary messenger systems, ion channel activity, cytoskeletal structure, and genetic expression $[2,106]$.

The activation of these pathways ultimately leads to new skin formation via a process known as tissue creep, which can further be divided into mechanical and biological creep $[109,110]$. Mechanical creep is an acute response to stretching where the viscoelasticity of skin allows it to deform in response to a loading or stretching force. This type of tissue expansion is temporary and is only secondary to the loading force which is applied. Biological creep, however, is when newly synthesized tissue is formed and is the final target of surgical tissue expansion. Biological creep occurs mainly due to increased activity in the dermal layer of the skin, such as fibroblast proliferation and collagen synthesis, supported by increased synthesis of myofilaments and neovascularization $[109,110]$.

\section{Environmental Factors}

Until 1975, scientists debated about the origin and nature of elastic fibres. It was finally agreed upon that elastotic fibres represent either the new formation of abnormal elastin or the transformation of collagen into abnormal elastin [111]. The environmental condition plays an important role in determining the effect on the skin. Extrinsic factors such as heat, sun, cold wind, and low and high humidity modify the microstructure of the skin. In addition, geographical, occupational, religious, and cultural factors have also been reported to affect human skin [112]; for instance, those who are doing outside work are more frequently exposed than those who are working inside.

\section{Sun Exposure}

Histologically, chronic sun exposure can cause extensive changes like wrinkles in dermal accumulation in the skin. In the normal state, elastin is found in the papillary dermis with a small diameter and arranged perpendicular to the epidermis. In deeper layers of the dermis, elastin is thicker and vertically oriented. Bouissou et al. [113] have reported that under sun exposure the elastin core became thinner and the fibroblasts became quiescent, while the elastotic degeneration was increased in the reticular dermis. The disintegration of elastic fibres increased in the papillary dermis with age, which resulted in reducing the elasticity of the skin. In contrast, Warren et al. [114] demonstrated that the elastin content increased with solar exposure, while the collagen content was decreased. By using immunohistochemical staining, the sun-protected tissue shows that the elastin was revealed as discrete fibres under the epidermis and sparsely in the dermis layer. The increase of the accumulation of elastic fibres under sun exposure was approved by Bernstein et al. [115].

Infrared radiation has a significantly negative effect on the skin. In vitro experiments on human fibroblasts have proven that even small doses of infrared radiation can produce free radicals, affect collagen and elastin expression, and upregulates MMPs [116].

In sun-exposed skin, the macromolecules like glycosaminoglycans (GAGs) and protein-bound proteoglycans are different compared to unexposed skin. The GAGs, especially hyaluronic acid, accumulate more under sun exposure $[112,117]$. The accumulated GAGs show reduced water-binding capabilities as well as a reduced ability to interact with other components in the dermal ECM [112]. All of these factors make the exposed skin become more wrinkled, saggy, dry, and thin.

\section{UV Radiation}

Exposure to UV radiation contributes to the extrinsic aging of the skin. By comparing UV-A and UV-B, Bernstein et al. [115] demonstrated that UV-B has higher elastin-promoter activity than UV-A. In the photoaged skin, the elastin appears discrete and sparsely distributed but becomes densely accumulated $[115,118]$. The effects of UV-B are quite distinguishable, where the skin becomes wrinkled and there is an increase in elastosis and tumour formation, but the UV-A changes the skin in the same way as chronological changes in aging mice [117]. By understanding all of these factors, we see that elastosis is actually comprised of two phases: (1) simple hyperplasia where the elastic fibres increase in number and thicker 


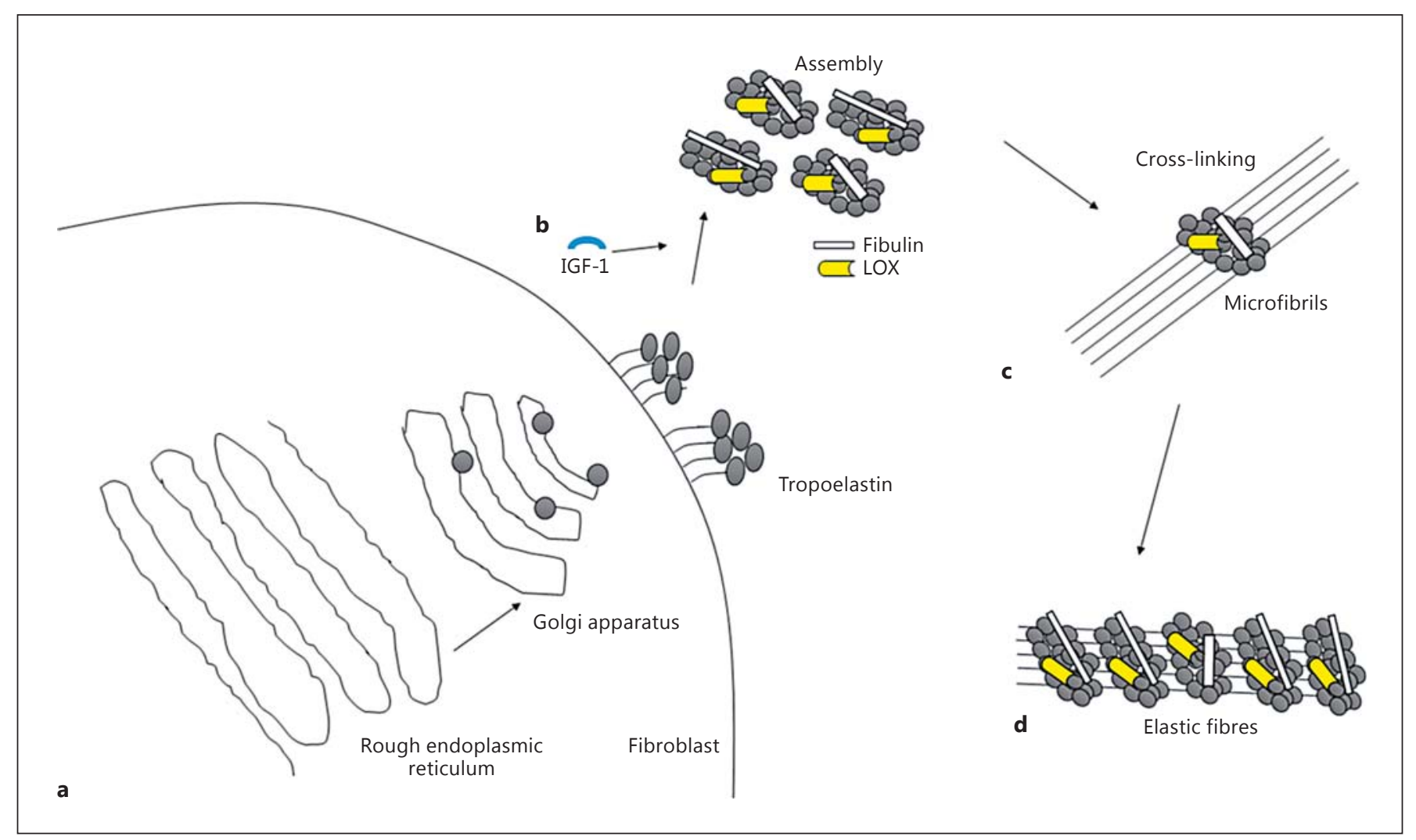

Fig. 5. The elastogenesis process at each respective stage. a Monomer synthesize. b Coacervation. c Cross-linking. d Packaging.

and (2) actinic degeneration where the radiant energy gives injury to the strength-giving protein elastin, making it fragile [119].

UV radiation induces the downregulation of collagen and elastic fibre synthesis by blocking the function of TGF- $\beta[120,121]$. UV radiation stimulates the upregulation of ROS (reactive oxygen species) and hydrogen peroxide but the downregulation of antioxidant enzymes [122]. By increasing ROS synthesis, it is likely to participate in the amplification of signals, leading to the activation of the MAPK pathway. Those MAPKs activate the AP-1 transcription factor and upregulate the MMPs [123]. The level of MMP-12 increases after UV exposure [124]. UV radiation also degrades TGF- $\beta$, which disrupts the deactivation of MMP-1 and MMP-3 [121, 125].

\section{Cigarette Smoke}

The elastic fibres can also be affected by smoking. Heavy smokers have demonstrated abnormalities of elastic fibres. Francès et al. [126] and Just et al. [127] have demonstrated that the mean relative area and the total number of elastic fibres were significantly increased among heavy smokers compared to non-smokers. The elastic fibres were more numerous, shorter, wider, and fragmented among smokers. The increased number is due to the degradation and fragmentation of elastin, as occurs in solar elastosis, rather than the newly synthesized elastic fibres [127]. A significantly different area $\left(15.3 \%\right.$ higher) and number of fibres $\left(667 / \mathrm{mm}^{2}\right)$ have been reported in the reticular dermis for smokers compared to non-smokers $\left(11.7 \%\right.$ and $557 / \mathrm{mm}^{2}$, respectively) [127]. These abnormalities are less obvious compared to solar elastosis [126].

Cigarette smoke inhibits the regulation of LOX, transcription of tropoelastin, and production of collagen type I [128]. Since LOX play a crucial role in the regulation of its expression, this downregulates the elastin as well as collagen $[129,130]$. The nicotine in cigarette smoke also inhibits the proliferation of fibroblasts [131]. Thus, smoking leads to decreased moisture in the stratum corneum of the facial skin, resulting in wrinkled skin [132]. Yin et al. $[133,134]$ have reported that tobacco smoke induced 


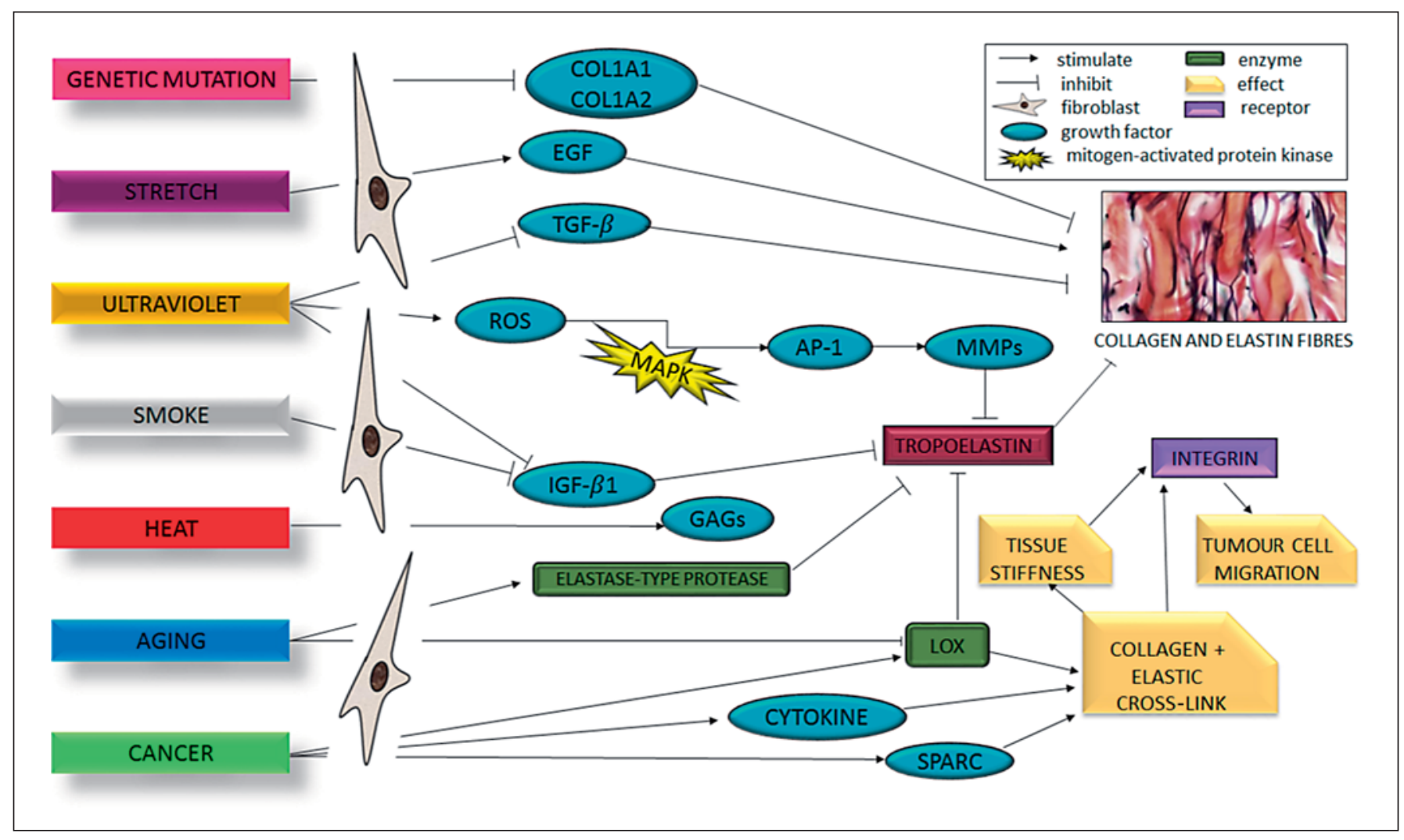

Fig. 6. Factors affecting the regulation of collagen and elastin homeostasis.

MMP-1, MMP-7, and MMP-3 but inhibited the production of type I and type III procollagen.

Tobacco smoke blocks cellular responsiveness to TGF-1 through the induction of its non-functional latent form and the downregulation of TGF- $\beta_{1}$ receptors [134]. Since TGF-1 is crucial for the stimulation of collagen and elastin production, hence those will be inhibited among smokers [132]. TGF-1 also acts as a positive growth factor, inducing the synthesis of ECM proteins. Hence, this TGF will not function very well since it is blocked by smoke.

\section{Nutraceutical and Cosmeceutical Applications}

The term nutraceuticals was coined in 1989 and is defined as foods or food products that provide medical or health benefits, while the term cosmeceuticals describes cosmetic products that claim to provide medical or health benefits $[135,136]$. With regard to application on human skin, some nutraceuticals and cosmeceuticals have been proven to have positive effects, most commonly involving wound healing and anti-aging properties. Virgin coconut oil, for example, has been shown to aid in wound healing by actively promoting the synthesis of ECM components such as collagen, elastic fibres, and GAGs [137]. The topical application of commercially available products containing retinol and vitamin $\mathrm{C}$ have been shown to be able to partially reverse skin changes induced by intrinsic and extrinsic aging [36]. Certain types of rice, namely red and black rice, possess phytochemicals that are notable antioxidants and anti-aging compounds such as $\gamma$-oryzanol, tocopherols, and tocotrienols [136]. Honey and aloe vera are also very well-known remedies that aid in wound healing as they possess angiogenic and neovascularization properties, stimulate the formation of granulation tissue, and enhance reepithelialization [138-140].

\section{Overview of Molecular Changes Affecting Collagen and Elastin Dynamics in Skin}

After understanding the changes that occur following various biological, physical, and environmental exposures, it was observed that many molecular components 
are involved in several pathways as opposed to being limited to only one specific molecular pathway. In addition, it was also observed that different factors affected these pathways via similar mechanisms by affecting similar components, despite being different in origin. LOX, for example, is induced in cases of carcinogenesis but inhibited in response to aging. When induced in carcinogenesis, LOX can stimulate collagen-elastin cross-linking, leading to tissue stiffness, but inhibition in response to aging will reduce tropoelastin synthesis, thus disrupting elastin formation. Another example is IGF- $\beta_{1}$, which is an important growth factor in elastin synthesis. Its synthesis can be blocked not only by exposure to UV radiation but by smoking as well. A model is proposed which illustrates how all these different mechanisms intersect and how the various internal and external factors described above can disrupt the homeostatic equilibrium of these pathways (fig. 5).

\section{Conclusion}

The pathways that regulate the synthesis, degradation, and maintenance of collagen and elastin networks in the skin are numerous and interrelated. As such, factors that affect one pathway are likely to indirectly affect other pathways as well (fig. 6). This review has proposed a holistic overview integrating the different molecular pathways that are affected by various biological, physical, and environmental factors. The changes that occur at the mo- lecular level in response to various stimuli involve numerous growth factors, gene expression pathways, and signalling molecules. Collectively, these changes are able to negatively affect the structural and mechanical integrity of collagen and elastin networks, thus affecting their functional capabilities. These changes also manifest as physical symptoms affecting skin such as hyperextensibility, dehydration, loss of elasticity, and wrinkling of the skin. A deeper understanding of how the dynamics of collagen and elastin networks in the skin are affected by internal and external factors of varying origin, and how these factors affect numerous components of different molecular pathways, could lead to better diagnostic and treatment methods of dermatological conditions.

\section{Acknowledgement}

This work was supported by a High Impact Research Grant from the Ministry of Education, Malaysia (UM.C/625/1/HIR/ MOHE/DENT/21).

\section{Statement of Ethics}

Ethical approval was provided by the Institutional Animal Care and Use Committee, University Putra Malaysia (UPM/IACUC/ AUP-R031/2013).

\section{Disclosure Statement}

The authors declare no conflicts of interests.

\section{References}

1 Silver FH, Freeman JW, DeVore D: Viscoelastic properties of human skin and processed dermis. Skin Res Technol 2001;7:18-23.

-2 Silver FH, Siperko LM, Seehra GP: Mechanobiology of force transduction in dermal tissue. Skin Res Technol 2003;9:3-23.

-3 Bischoff JE, Arruda EM, Grosh K: Finite element modeling of human skin using an isotropic, nonlinear elastic constitutive model. J Biomech 2000;33:645-652.

4 Silver FH, Kato YP, Ohno M, Wasserman AJ: Analysis of mammalian connective tissue: relationship between hierarchical structures and mechanical properties. J Long Term Eff Med Implants 1992;2:165-198.

5 Vitellaro-Zuccarello L, Cappelletti S, Dal Pozzo Rossi V, Sari-Gorla M: Stereological analysis of collagen and elastic fibers in the normal human dermis: variability with age, sex, and body region. Anat Rec 1994;238:153-162.
6 6 Wenger MPE, Laurent B, Horton MA, Patrick M: Mechanical properties of collagen fibrils. Biophys J 2007;93:1255-1263.

7 Fratzl P: Collagen: Structure and Mechanics. Berlin, Springer, 2008.

8 Osman OS, Selway JL, Harikumar PE, Stocker CJ, Wargent ET, Cawthorne MA, et al: A novel method to assess collagen architecture in skin. BMC Bioinformatics 2013;14:260.

-9 Shoulders MD, Raines RT: Collagen structure and stability. Annu Rev Biochem 2009;78: 929-958.

10 Gelse K: Collagens - structure, function, and biosynthesis. Adv Drug Deliv Rev 2003;55: 1531-1546.

11 Sherman VR, Yang W, Meyers MA: The materials science of collagen. J Mech Behav Biomed Mater 2015;52:22-50.
2 Veit G, Kobbe B, Keene DR, Paulsson M, Koch M, Wagener R: Collagen XXVIII, a novel von Willebrand factor A domain-containing protein with many imperfections in the collagenous domain. J Biol Chem 2006;281: 3494-3504.

$\checkmark 13$ Baldwin SJ, Quigley AS, Clegg C, Kreplak L: Nanomechanical mapping of hydrated rat tail tendon collagen I fibrils. Biophys J 2014;107: 1794-1801.

14 Tzaphlidou M: The role of collagen and elastin in aged skin: an image processing approach. Micron 2004;35:173-177.

15 Birk DE, Zycband EI, Winkelmann DA, Trelstad RL: Collagen fibrillogenesis in situ: fibril segments are intermediates in matrix assembly. Proc Natl Acad Sci USA 1989;86:45494553. 
16 Bozec L, van der Heijden G, Horton M: Collagen fibrils: nanoscale ropes. Biophys J 2007; 92:70-75.

17 Orgel JP, San Antonio JD, Antipova O: Molecular and structural mapping of collagen fibril interactions. Connect Tissue Res 2011;52: 2-17.

18 Vuorio E, de Crombrugghe B: The family of collagen genes. Annu Rev Biochem 1990;59: 837-872.

19 Fratzl P, Peter F, Klaus M, Ivo Z, Gert R, Heinz A, et al: Fibrillar structure and mechanical properties of collagen. J Struct Biol 1998 122:119-122.

20 Sasaki N, Naoki S, Singo O: Stress-strain curve and Young's modulus of a collagen molecule as determined by the X-ray diffraction technique. J Biomech 1996;29:655-658.

21 Shen ZL, Dodge MR, Kahn H, Ballarini R, Eppell SJ: Stress-strain experiments on individual collagen fibrils. Biophys J 2008;95:39563963.

22 McKee CT, Last JA, Paul R, Murphy CJ: Indentation versus tensile measurements of Young's modulus for soft biological tissues. Tissue Eng Part B Rev 2011;17:155-164.

-23 Licup AJ, Münster S, Sharma A, Sheinman M, Jawerth LM, Fabry B, et al: Stress controls the mechanics of collagen networks. Proc Natl Acad Sci USA 2015;112:9573-9578.

24 Fung YC: Elasticity of soft tissues in simple elongation. Am J Physiol 1967;213:15321544.

25 Graham JS, Vomund AN, Phillips CL, Grandbois $\mathrm{M}$ : Structural changes in human type I collagen fibrils investigated by force spectroscopy. Exp Cell Res 2004;299:335-342.

-26 Münster S, Jawerth LM, Leslie BA, Weitz JI, Fabry B, Weitz DA: Strain history dependence of the nonlinear stress response of fibrin and collagen networks. Proc Natl Acad Sci USA 2013;110:12197-12202.

-27 Gosline J, Lillie M, Carrington E, Guerette P, Ortlepp C, Savage K: Elastic proteins: biological roles and mechanical properties. Philos Trans R Soc Lond B Biol Sci 2002;357:121-132.

28 Holzapfel G, G H: Biomechanics of soft tissue; in LeMaitre J (ed): Handbook of Materials Behavior Models. San Diego, Academic Press, 2001, pp 1057-1071.

29 Oxlund H, Hans O, Jan M, Viidik A: The role of elastin in the mechanical properties of skin. J Biomech 1988;21:213-218.

- 30 Yeo GC, Baldock C, Tuukkanen A, Roessle M, Dyksterhuis LB, Wise SG, et al: Tropoelastin bridge region positions the cell-interactive $\mathrm{C}$ terminus and contributes to elastic fiber assembly. Proc Natl Acad Sci USA 2012;109: 2878-2883.

- 31 Kozel BA, Rongish BJ, Czirok A, Zach J, Little $\mathrm{CD}$, Davis EC, et al: Elastic fiber formation: a dynamic view of extracellular matrix assembly using timer reporters. J Cell Physiol 2006; 207:87-96.
Sato F, Wachi H, Starcher BC, Murata H, Amano S, Tajima S, et al: The characteristics of elastic fiber assembled with recombinant tropoelastin isoform. Clin Biochem 2006;39: 746-753.

33 Vrhovski B, Bernadette V, Weiss AS: Biochemistry of tropoelastin. Eur J Biochem 1998;258:1-18.

34 Rauscher S, Pomès R: Structural disorder and protein elasticity. Adv Exp Med Biol 2012; 725:159-183.

35 Kazlouskaya V, Malhotra S, Lambe J, Idriss MH, Elston D, Andres C: The utility of elastic Verhoeff-Van Gieson staining in dermatopathology. J Cutan Pathol 2013;40:211-225.

36 Seité S, Bredoux C, Compan D, Zucchi H, Lombard D, Medaisko C, et al: Histological evaluation of a topically applied retinol-vitamin C combination. Skin Pharmacol Physiol 2005; 18:81-87.

37 Proctor GB, Horobin RW: Chemical structures and staining mechanisms of Weigert's resorcin-fuchsin and related elastic fiber stains. Stain Technol 1988;63:101-111.

38 Flotte TJ, Seddon JM, Zhang YQ, Glynn RJ, Egan KM, Gragoudas ES: A computerized image analysis method for measuring elastic tissue. J Invest Dermatol 1989;93:358-362.

39 Montagna W, William M, Kay C: Structural changes in aging human skin. J Invest Dermatol 1979;73:47-53.

40 Zweers MC, van Vlijmen-Willems IM, van Kuppevelt TH, Mecham RP, Steijlen PM, Bristow J, et al: Deficiency of tenascin-X causes abnormalities in dermal elastic fiber morphology. J Invest Dermatol 2004;122:885-891.

-41 Braverman IM, Fonferko E: Studies in cutaneous aging. I. The elastic fiber network. J Invest Dermatol 1982;78:434-443.

42 Mecham RP: Elastin synthesis and fiber assembly. Ann NY Acad Sci 1991;624:137-146.

43 Nivison-Smith L, Weiss AS: Alignment of human vascular smooth muscle cells on parallel electrospun synthetic elastin fibers. J Biomed Mater Res A 2012;100:155-161.

44 Hinek A, Rabinovitch M: 67-kD elastin-binding protein is a protective 'companion' of extracellular insoluble elastin and intracellular tropoelastin. J Cell Biol 1994;126:563-574.

-45 Bunda S, Severa B, Peter L, Yanting W, Kela $\mathrm{L}$, Aleksander $\mathrm{H}$ : Aldosterone induces elastin production in cardiac fibroblasts through activation of insulin-like growth factor-i receptors in a mineralocorticoid receptor-independent manner. Am J Pathol 2007;171:809-819.

46 Yanagisawa H, Davis EC: Unraveling the mechanism of elastic fiber assembly: the roles of short fibulins. Int J Biochem Cell Biol 2010; 42:1084-1093.

47 Horiguchi M, Inoue T, Ohbayashi T, Hirai M, Noda K, Marmorstein LY, et al: Fibulin-4 conducts proper elastogenesis via interaction with cross-linking enzyme lysyl oxidase. Proc Natl Acad Sci USA 2009;106:19029-19034.
8 Papke CL, Yanagisawa H: Fibulin-4 and fibulin-5 in elastogenesis and beyond: insights from mouse and human studies. Matrix Biol 2014;37:142-149.

49 Wagenseil JE, Mecham RP: New insights into elastic fiber assembly. Birth Defects Res C Embryo Today 2007;81:229-240.

50 Kothapalli CR, Ramamurthi A: Lysyl oxidase enhances elastin synthesis and matrix formation by vascular smooth muscle cells. J Tissue Eng Regen Med 2009;3:655-661.

51 Umeda H, Aikawa M, Libby P: Liberation of desmosine and isodesmosine as amino acids from insoluble elastin by elastolytic proteases. Biochem Biophys Res Commun 2011;411: 281-286.

52 Shapiro SD, Endicott SK, Province MA, Pierce JA, Campbell EJ: Marked longevity of human lung parenchymal elastic fibers deduced from prevalence of $\mathrm{D}$-aspartate and nuclear weapons-related radiocarbon. J Clin Invest 1991;87:1828-1834

53 Basalyga DM: Elastin degradation and calcification in an abdominal aorta injury model: role of matrix metalloproteinases. Circulation 2004;110:3480-3487.

54 Myllyharju J, Johanna M, Kivirikko KI: Collagens and collagen-related diseases. Ann Med 2001;33:7-21.

55 Ricard-Blum S: The collagen family. Cold Spring Harb Perspect Biol 2011;3:a004978.

56 Dalgleish R: The human type I collagen mutation database. Nucleic Acids Res 1997;25: 181-187.

57 Bodian DL, Madhan B, Brodsky B, Klein TE: Predicting the clinical lethality of osteogenesis imperfecta from collagen glycine mutations. Biochemistry 2008;47:5424-5432.

58 Beck K, Chan VC, Shenoy N, Kirkpatrick A, Ramshaw JA, Brodsky B: Destabilization of osteogenesis imperfecta collagen-like model peptides correlates with the identity of the residue replacing glycine. Proc Natl Acad Sci USA 2000;97:4273-4278.

59 Willing MC, Deschenes SP, Slayton RL, Roberts EJ: Premature chain termination is a unifying mechanism for COL1A1 null alleles in osteogenesis imperfecta type I cell strains. Am J Hum Genet 1996;59:799-809.

60 Körkkö J, Ala-Kokko L, De Paepe A, Nuytinck L, Earley J, Prockop DJ: Analysis of the COL1A1 and COL1A2 genes by PCR amplification and scanning by conformation-sensitive gel electrophoresis identifies only COL1A1 mutations in 15 patients with osteogenesis imperfecta type I: identification of common sequences of null-allele mutations. Am J Hum Genet 1998;62:98-110.

61 Malfait F, Wenstrup RJ, De Paepe A: Clinical and genetic aspects of Ehlers-Danlos syndrome, classic type. Genet Med 2010;12:597605

62 Bateman JF, Boot-Handford RP, Lamandé SR: Genetic diseases of connective tissues: cellular and extracellular effects of ECM mutations. Nat Rev Genet 2009;10:173-183.
Stress-Responsive Changes in Collagen and Elastin Networks in Skin
Skin Pharmacol Physiol 2016;29:190-203 DOI: $10.1159 / 000447017$ 
63 Van Agtmael T, Bruckner-Tuderman L: Basement membranes and human disease. Cell Tissue Res 2010;339:167-188.

64 Lampe AK: Collagen VI-related muscle disorders. J Med Genet 2005;42:673-685.

65 Carter EM, Raggio CL: Genetic and orthopedic aspects of collagen disorders. Curr Opin Pediatr 2009;21:46-54.

-66 Andiran N, Sarikayalar F, Saraçlar M, Cağlar M: Autosomal recessive form of congenital cutis laxa: more than the clinical appearance. Pediatr Dermatol 2002;19:412-414.

-67 Marchase P, Holbrook K, Pinnell SR: A familial cutis laxa syndrome with ultrastructural abnormalities of collagen and elastin. J Invest Dermatol 1980;75:399-403.

68 Ringpfeil F: Selected disorders of connective tissue: pseudoxanthoma elasticum, cutis laxa, and lipoid proteinosis. Clin Dermatol 2005 23:41-46.

-69 Turner-Stokes L, Turton C, Pope FM, Green M: Emphysema and cutis laxa. Thorax 1983 38:790-792.

-70 Szabo Z, Crepeau MW, Mitchell AL, Stephan MJ, Puntel RA, Yin Loke K, et al: Aortic aneurysmal disease and cutis laxa caused by defects in the elastin gene. J Med Genet 2006;43:255258 .

71 Loeys B: Homozygosity for a missense mutation in fibulin-5 (FBLN5) results in a severe form of cutis laxa. Hum Mol Genet 2002;11 2113-2118

-72 Tassabehji M: An elastin gene mutation producing abnormal tropoelastin and abnormal elastic fibres in a patient with autosomal dominant cutis laxa. Hum Mol Genet 1998;7: 1021-1028.

73 Fang M, Yuan J, Peng C, Li Y: Collagen as a double-edged sword in tumor progression. Tumour Biol 2014;35:2871-2882.

-74 Arnold SA, Rivera LB, Miller AF, Carbon JG, Dineen SP, Xie Y, et al: Lack of host SPARC enhances vascular function and tumor spread in an orthotopic murine model of pancreatic carcinoma. Dis Model Mech 2009;3:57-72.

-75 Levental KR, Yu H, Kass L, Lakins JN, Egeblad $\mathrm{M}$, Erler JT, et al: Matrix crosslinking forces tumor progression by enhancing integrin signaling. Cell 2009;139:891-906

76 Nagase H, Visse R, Murphy G: Structure and function of matrix metalloproteinases and TIMPs. Cardiovasc Res 2006;69:562-573.

77 Chernov AV, Strongin AY: Epigenetic regulation of matrix metalloproteinases and their collagen substrates in cancer. Biomol Concepts 2011;2:135-147.

-78 Huijbers IJ, Iravani M, Popov S, Robertson D, Al-Sarraj S, Jones C, et al: A role for fibrillar collagen deposition and the collagen internalization receptor endo180 in glioma invasion. PLoS One 2010;5:e9808.

79 Barcus CE, Keely PJ, Eliceiri KW, Schuler LA: Stiff collagen matrices increase tumorigenic prolactin signaling in breast cancer cells. J Biol Chem 2013;288:12722-12732.
80 Wyckoff JB, Wang Y, Lin EY, Li J-F, Goswami $S$, Stanley ER, et al: Direct visualization of macrophage-assisted tumor cell intravasation in mammary tumors. Cancer Res 2007;67: 2649-2656.

-81 Erler JT, Bennewith KL, Cox TR, Lang G, Bird D, Koong A, et al: Hypoxia-induced lysyl oxidase is a critical mediator of bone marrow cell recruitment to form the premetastatic niche. Cancer Cell 2009;15:35-44.

82 Kaplan RN, Riba RD, Zacharoulis S, Bramley AH, Vincent L, Costa C, et al: VEGFR1-positive haematopoietic bone marrow progenitors initiate the pre-metastatic niche. Nature 2005;438:820-827.

83 Velling T, Risteli J, Wennerberg K, Mosher DF, Johansson S: Polymerization of type I and III collagens is dependent on fibronectin and enhanced by integrins $\alpha_{11} \beta_{1}$ and $\alpha_{2} \beta_{1}$. J Biol Chem 2002;277:37377-37381.

84 Wölfle U, Seelinger G, Bauer G, Meinke MC, Lademann J, Schempp CM: Reactive molecule species and antioxidative mechanisms in normal skin and skin aging. Skin Pharmacol Physiol 2014;27:316-332.

85 El-Domyati M, Attia S, Saleh F, Brown D, Birk DE, Gasparro F, et al: Intrinsic aging vs. photoaging: a comparative histopathological, immunohistochemical, and ultrastructural study of skin. Exp Dermatol 2002;11:398405.

86 Lavker RM: Structural alterations in exposed and unexposed aged skin. J Invest Dermatol 1979;73:59-66.

87 Foster JA, Rich CB, Miller M, Benedict MR, Richman RA, Florini JR: Effect of age and IGF-I administration on elastin gene expression in rat aorta. J Gerontol 1990;45:B113B118.

88 Quaglino D, Fornieri C, Nanney LB, Davidson JM: Extracellular matrix modifications in rat tissues of different ages. Correlations between elastin and collagen type I mRNA expression and lysyl-oxidase activity. Matrix 1993;13:481-490.

89 Sator PG, Schmidt JB, Sator MO, Huber JC, Hönigsmann $\mathrm{H}$ : The influence of hormone replacement therapy on skin ageing: a pilot study. Maturitas 2001;39:43-55.

90 Robert L, Labat-Robert J, A.-M. R: Physiology of skin aging. Pathol Biol 2009;57:336-341.

-91 Labat-Robert J, Fourtanier A, Boyer-Lafargue B, Robert L: Age-dependent increase of elastase type protease activity in mouse skin: effect of UV-irradiation. J Photochem Photobiol B 2000;57:113-118.

$92 \mathrm{Ma}$ W, Wlaschek M, Tantcheva-Poór I, Schneider LA, Naderi L, Razi-Wolf Z, et al: Chronological ageing and photoageing of the fibroblasts and the dermal connective tissue. Clin Exp Dermatol 2001;26:592-599.

93 Dunn MG, Silver FH: Viscoelastic behavior of human connective tissues: relative contribution of viscous and elastic components. Connect Tissue Res 1983;12:59-70.
94 Dunn MG, Silver FH, Swann DA: Mechanical analysis of hypertrophic scar tissue: structural basis for apparent increased rigidity. J Invest Dermatol 1985;84:9-13.

$\$ 95$ Humphrey JD, Dufresne ER, Schwartz MA Mechanotransduction and extracellular matrix homeostasis. Nat Rev Mol Cell Biol 2014;15:802-812.

96 Chiquet M, Renedo AS, Huber F, Flück M How do fibroblasts translate mechanical signals into changes in extracellular matrix production? Matrix Biol 2003;22:73-80.

97 Nguyen TD, Liang R, Woo SL-Y, Burton SD, Wu C, Almarza A, et al: Effects of cell seeding and cyclic stretch on the fiber remodeling in an extracellular matrix-derived bioscaffold. Tissue Eng Part A 2009;15:957-963.

98 Chang ALS, Agredano YZ, Kimball AB: Risk factors associated with striae gravidarum. J Am Acad Dermatol 2004;51:881-885.

-99 Kasielska-Trojan A, Sobczak M, Antoszewski B: Risk factors of striae gravidarum. Int J Cosmet Sci 2015;37:236-240.

100 Osman H, Rubeiz N, Tamim H, Nassar AH: Risk factors for the development of striae gravidarum. Am J Obstet Gynecol 2007;196: 62.e1-5.

101 Thomas RGR, Liston WA: Clinical associations of striae gravidarum. J Obstet Gynaecol 2004;24:270-271.

102 Cordeiro RCT, Zecchin KG, de Moraes AM: Expression of estrogen, androgen, and glucocorticoid receptors in recent striae distensae. Int J Dermatol 2010;49:30-32.

103 Liu DT: Letter: striae gravidarum. Lancet 1974;1:625.

104 Tunzi M, Gray GR: Common skin conditions during pregnancy. Am Fam Physician 2007;75:211-218

105 Neumann CG: The expansion of an area of skin by progressive distention of a subcutaneous balloon; use of the method for securing skin for subtotal reconstruction of the ear. Plast Reconstr Surg 1957;19:124-130.

106 De Filippo RE, Atala A: Stretch and growth: the molecular and physiologic influences of tissue expansion. Plast Reconstr Surg 2002; 109:2450-2462.

107 Takei T, Mills I, Arai K, Sumpio BE: Molecular basis for tissue expansion: clinical implications for the surgeon. Plast Reconstr Surg 1998;102:247-258.

108 Zöllner AM, Buganza Tepole A, Kuhl E: On the biomechanics and mechanobiology of growing skin. J Theor Biol 2012;297:166175 .

109 Austad ED, Thomas SB, Pasyk K: Tissue expansion: dividend or loan? Plast Reconstr Surg 1986;78:63-67.

110 Johnson PE, Kernahan DA, Bauer BS: Dermal and epidermal response to soft-tissue expansion in the pig. Plast Reconstr Surg 1988;81:390-397.

111 O'Brien JP: Actinic granuloma. An annular connective tissue disorder affecting sun- and heat-damaged (elastotic) skin. Arch Dermatol 1975;111:460-466. 
112 Benedetto AV: The environment and skin aging. Clin Dermatol 1998;16:129-139.

113 Bouissou H, Pieraggi MT, Julian M, Savit T: The elastic tissue of the skin. A comparison of spontaneous and actinic (solar) aging. Int J Dermatol 1988;27:327-335.

114 Warren R, Gartstein V, Kligman AM, Montagna W, Allendorf RA, Ridder GM: Age, sunlight, and facial skin: a histologic and quantitative study. J Am Acad Dermatol 1991;25:751-760.

-115 Bernstein EF, Brown DB, Urbach F, Forbes $\mathrm{D}$, Del Monaco M, Wu M, et al: Ultraviolet radiation activates the human elastin promoter in transgenic mice: a novel in vivo and in vitro model of cutaneous photoaging. J Invest Dermatol 1995;105:269-273.

-116 Robert C, Bonnet M, Marques S, Numa M, Doucet O: Low to moderate doses of infrared A irradiation impair extracellular matrix homeostasis of the skin and contribute to skin photodamage. Skin Pharmacol Physiol 2015;28:196-204.

-117 Bissett DL, Hannon DP, Orr TV: An animal model of solar-aged skin: histological, physical, and visible changes in UV-irradiated hairless mouse skin. Photochem Photobiol 1987;46:367-378.

-118 Moloney SJ, Edmonds SH, Giddens LD, Learn DB: The hairless mouse model of photoaging: evaluation of the relationship between dermal elastin, collagen, skin thickness and wrinkles. Photochem Photobiol 1992;56:505-511.

-119 O’Brien JP, Regan W: A study of elastic tissue and actinic radiation in 'aging', temporal arteritis, polymyalgia rheumatica, and atherosclerosis. The actinic storm in the modern world. J Am Acad Dermatol 1991;24: 765-776.

120 Rittié L, Fisher GJ: UV-light-induced signal cascades and skin aging. Ageing Res Rev 2002;1:705-720.
121 Quan T, He T, Kang S, Voorhees JJ, Fisher GJ: Solar ultraviolet irradiation reduces collagen in photoaged human skin by blocking transforming growth factor- $\beta$ type II receptor/Smad signaling. Am J Pathol 2004;165: 741-751.

122 Masaki H: Role of antioxidants in the skin: anti-aging effects. J Dermatol Sci 2010;58: 85-90.

123 Cho Y, Yuri C, Son HJ, Eun-Mee K, Choi JH, Kim ST, et al: Doxycycline is neuroprotective against nigral dopaminergic degeneration by a dual mechanism involving MMP-3. Neurotox Res 2009;16:361-371.

124 Fortino V, Maioli E, Torricelli C, Davis P, Valacchi G: Cutaneous MMPs are differently modulated by environmental stressors in old and young mice. Toxicol Lett 2007;173: 73-79.

125 Gressner AM, Axel, Gressner M: Roles of TGF- $\beta$ in hepatic fibrosis. Front Biosci 2002; 7:d793.

126 Francès C, Boisnic S, Hartmann DJ, Dautzenberg B, Branchet MC, Charpentier YL, et al: Changes in the elastic tissue of the nonsun-exposed skin of cigarette smokers. Br J Dermatol 1991;125:43-47.

-127 Just M, Ribera M, Monsó E, Lorenzo JC, Ferrándiz $\mathrm{C}$ : Effect of smoking on skin elastic fibres: morphometric and immunohistochemical analysis. Br J Dermatol 2007;156: 85-91.

128 Gao S, Chen K, Zhao Y, Rich CB, Chen L, Li SJ, et al: Transcriptional and posttranscriptional inhibition of lysyl oxidase expression by cigarette smoke condensate in cultured rat fetal lung fibroblasts. Toxicol Sci 2005;87: 197-203.
129 Hautamaki RD, Kobayashi DK, Senior RM, Shapiro SD: Requirement for macrophage elastase for cigarette smoke-induced emphysema in mice. Science 1997;277:20022004.

130 Shapiro SD, Goldstein NM, Houghton AM, Kobayashi DK, Kelley D, Belaaouaj A: Neutrophil elastase contributes to cigarette smoke-induced emphysema in mice. Am J Pathol 2003;163:2329-2335.

131 Jorgensen LN, Kallehave F, Christensen E, Siana JE, Gottrup F: Less collagen production in smokers. Surgery 1998;123:450-455.

132 Morita A: Tobacco smoke causes premature skin aging. J Dermatol Sci 2007;48:169-175.

133 Yin L, Morita A, Tsuji T: Alterations of extracellular matrix induced by tobacco smoke extract. Arch Dermatol Res 2000;292:188194.

134 Yin L, Morita A, Tsuji T: Tobacco smoke extract induces age-related changes due to modulation of TGF- $\beta$. Exp Dermatol 2003; 12(suppl 2):51-56.

135 Kalra EK: Nutraceutical - definition and introduction. AAPS PharmSci 2003;5:E25.

136 Chulasiri M: Antiaging cosmeceuticals from pigmented rice. Asian J Pharm Sci 2016;11: 30.

137 Nevin KG, Rajamohan T: Effect of topical application of virgin coconut oil on skin components and antioxidant status during dermal wound healing in young rats. Skin Pharmacol Physiol 2010;23:290-297.

138 Davis SC, Perez R: Cosmeceuticals and natural products: wound healing. Clin Dermatol 2009;27:502-506.

139 Bergman A, Yanai J, Weiss J, Bell D, David MP: Acceleration of wound healing by topical application of honey. An animal model. Am J Surg 1983;145:374-376.

140 Moon EJ, Lee YM, Lee OH, Lee MJ, Lee SK, Chung $\mathrm{MH}$, et al: A novel angiogenic factor derived from Aloe vera gel: $\beta$-sitosterol, a plant sterol. Angiogenesis 1999;3:117-123.
Stress-Responsive Changes in Collagen and Elastin Networks in Skin
Skin Pharmacol Physiol 2016;29:190-203 DOI: $10.1159 / 000447017$ 